\title{
Group G Streptococcal Arthritis and Bowel Disease: A Rare Enteropathic Arthropathy
}

\author{
Stephen W. Trenkner, ${ }^{1}$ Ethan M. Braunstein, ${ }^{1}$ Matthew D. Lynn, ${ }^{1}$ and Robert W. Ike ${ }^{2}$ \\ Departments of ${ }^{1}$ Radiology and ${ }^{2}$ Medicine, Rheumatology Division, University of Michigan Medical Center, \\ Ann Arbor, Michigan, USA
}

\begin{abstract}
Group G streptococci may be seen as normal flora in many parts of the body, including the gastrointestinal tract. They are rarely pathogens in humans, but they have been isolated from septic joints in debilitated patients. Three patients with group $\mathrm{G}$ streptococcal arthritis were further evaluated using contrast studies of the colon. Abnormalities, including an occult carcinoma and a colocutaneous fistula, were found. We conclude that group G streptococcal arthritis may be associated with gastrointestinal abnormalities that allow a portal of entry for an otherwise innocuous organism, and that this represents a rare enteropathic arthropathy.
\end{abstract}

Key words: Arthropathy, group G streptococci.

The association of articular abnormality and gastrointestinal disease has been termed enteropathic arthropathy. Commonly recognized entities of this type include the arthritis of ulcerative colitis, Crohn's disease, and Whipple's disease [1]. In recent years we have noticed an association between group $G$ streptococcal arthritis and abnormalities of the bowel. Group $\mathrm{G}$ streptococci are normal flora in the gastrointestinal tract, but they may become pathogenic when a disruption of the bowel creates a portal of entry into the blood stream. We suggest barium evaluation of the gastrointestinal tract for any patient with group $\mathrm{G}$ streptococcal arthritis.

Address reprint requests to: Stephen W. Trenkner, M.D., Department of Radiology, Box 30, University Hospital, Ann Arbor, MI 48109-0030, USA

\section{Material and Methods}

Between July, 1981, and June, 1984, 3 patients with cultureproven group $\mathrm{G}$ streptococcal arthritis were evaluated. Their records and radiographs of the involved joints and gastrointestinal tract were reviewed.

\section{Case Reports}

\section{Case 1}

A 76-year-old woman presented with pain and swelling in the right knee of 20 days duration. Radiographs of the right knee demonstrated a large joint effusion and moderate degenerative changes. Turbid joint fluid was aspirated, which grew group $G$ streptococci. Despite no occult blood in the stools, a doublecontrast barium enema was performed. This demonstrated a large plaquelike lesion in the proximal ascending colon (Fig. 1). A right hemicolectomy was performed, revealing a Dukes C carcinoma of the colon with positive lymph nodes.

\section{Case 2}

A 35-year-old woman with a 17-year history of systemic lupus erythematosis (SLE) presented with shaking chills and a temperature of $104^{\circ}$. She had bilateral wrist pain.

Radiographs of the right wrist (Fig. 2A) showed radiocarpal cartilage loss and bone destruction at the scapholunate articulation. Although there may be such cartilage loss in SLE, the local osseous destruction in the presence of the onset of systemic symptoms suggested superimposed septic arthritis.

Purulent aspirate from the wrist grew group G steptococci.

A fistulogram of a draining sinus in the left lower quadrant of the abdomen demonstrated a colocutaneous fistula (Fig. 2B). The patient had undergone a diverting colostomy with formation of a Hartmann's pouch for diverticulitis 10 months earlier. The fistula extended from the end of the Hartmann's pouch to the skin.

\section{Case 3}

An 89-year-old man was admitted because of disorientation. Two days prior to admission he had fallen off a tractor and 


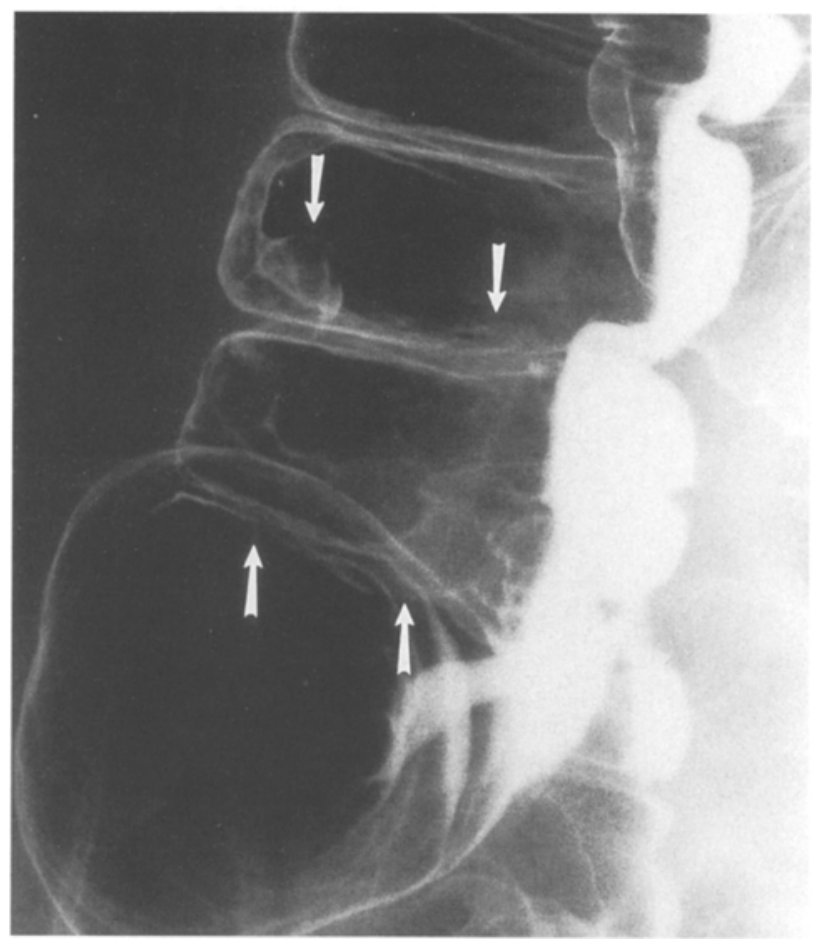

Fig. 1. Case 1. The left decubitus view from the barium enema demonstrated a plaquelike lesion in the proximal ascending colon (arrows).

Fig. 2. Case 2. A A radiograph of the right wrist of this 35-year-old woman showed radiocarpal narrowing with cortical destruction at the junction of the scaphoid and lunate (arrow). The findings were suggestive of septic arthritis superimposed on the patient's known SLE. B The fistulogram demonstrated communication between the skin and sigmoid colon.
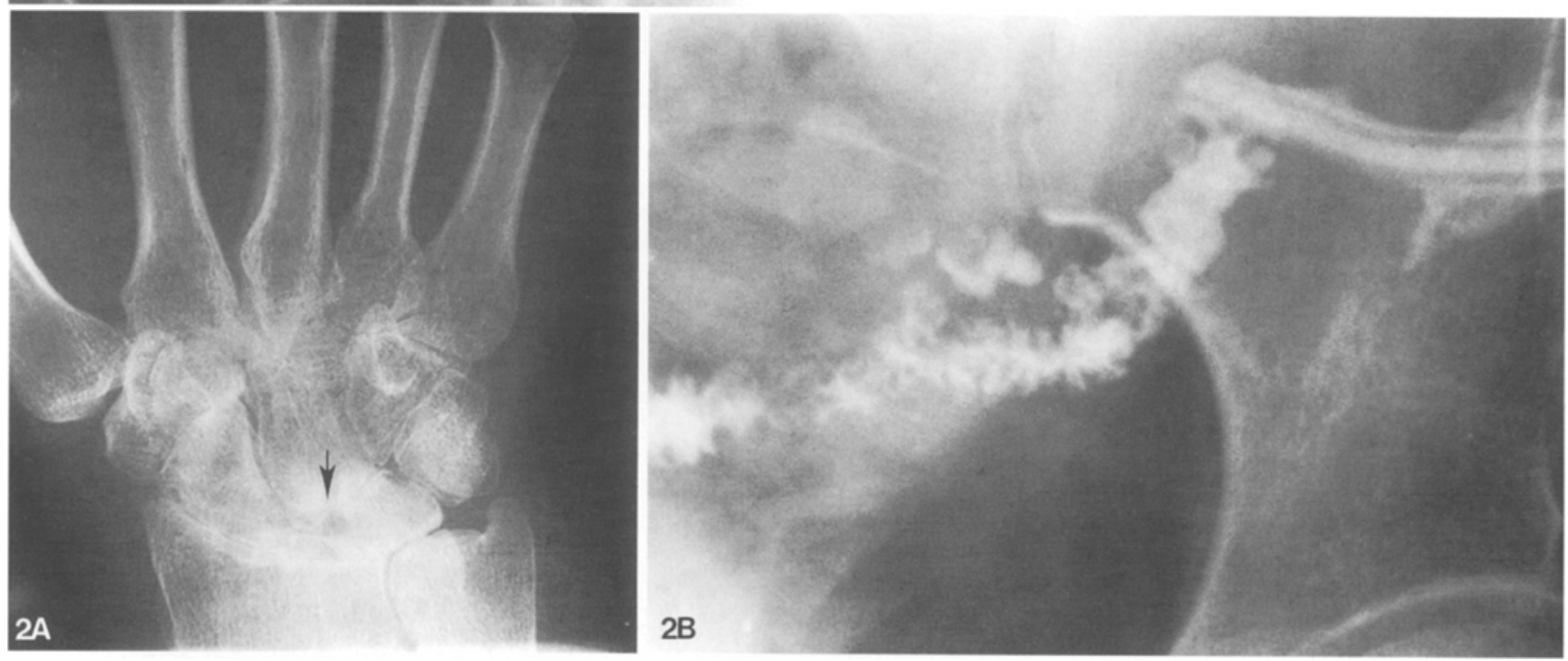

bumped his right shoulder. The shoulder was swollen, erythematous, and tender.

Radiographs of the right shoulder demonstrated degenerative changes but no specific findings of septic arthritis. Purulent material, culture-positive for group G streptococci, was aspirated from the right shoulder.

A barium enema demonstrated extensive diverticulosis as well as herniation of the transverse colon through the esophageal hiatus of the diaphragm (Fig. 3).

All of the patients were treated successfully with penicillin or vancomycin.

\section{Discussion}

Group G streptococci may be seen as normal flora in the pharynx and skin and genital, respiratory, and gastrointestinal tracts [2]. Although rarely pathogenic in humans, they have been isolated from septic joints in several reports [2-8].

The clinical presentation of our patients was typical of septic arthritis in general with swollen, tender joints. Two of the three patients had involvement of a single joint, which is typical of septic arthritis caused by common organisms [9]. One patient had polyarticular involvement, which has been reported to be frequent in patients with group $\mathrm{G}$ streptococcal infections [2].

These cases emphasize the difficulty in making the radiographic diagnosis of pyogenic arthritis. The clinical course is much faster than the radio- 


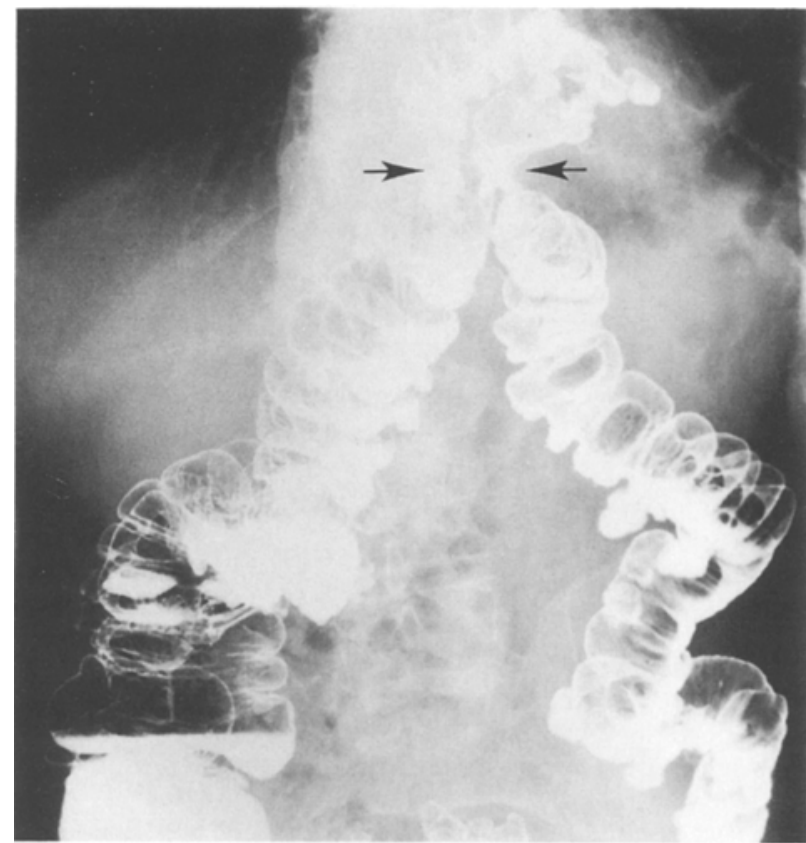

Fig. 3. Case 3. An upright view from a barium enema demonstrated extensive diverticulosis and herniation (arrows) of the transverse colon.

logic changes, which may be manifested early only by local osteoporosis, subtle changes in the joint space, and poorly defined cortical destruction. Although the findings in streptococcal $\mathrm{G}$ arthritis are similar to those in other forms of septic arthritis, the diagnosis was difficult radiographically because of underlying disease in the septic joints of our patients with SLE and degenerative joint disease.

Group G streptococcal arthritis most commonly occurs in patients with predisposing underlying conditions such as alcoholism, cancer, and diabetes [2-4]. It also occurs in patients with rheumatoid arthritis, particularly those with total joint arthroplasties $[5,6]$. Our patients had debilitating conditions including carcinoma of the colon and SLE. Our third patient had no known predisposing condition but was 89 years old and was possibly debilitated on that basis.

Watsky et al., in a report of patients with group $\mathrm{G}$ bacteremia, postulated that a breakdown of anatomical barriers to infection may be more important than the underlying debilitating condition [8]. Many of their patients had skin abnormalities such as cellulitis and decubitus ulcers that may have provided a portal of entry for the organism.

The association between group $\mathrm{G}$ streptococcal infections and malignancies is well documented [8, 10]. Rose reported a case of group G streptococcal endocarditis in a patient with adenocarcinoma of the colon [11].
All of our patients had colon abnormalities, documented by contrast studies, at the time of their septic arthritis. It is uncertain whether the colon cancer in case 1 altered the patient's response to infection (rendering her more susceptible to an organism of low virulence), or whether the tumor provided a portal of entry for the organism through the colon. In case 2 , the colocutaneous fistula was a likely portal of entry for the organism in a patient debilitated by SLE. The underlying reason for group $G$ septic arthritis in our third patient is less evident. The role of trauma, diverticulosis, or colonic herniation in the development of his septic arthritis is unknown.

Group $G$ streptococcal arthritis is rare. When identified, it should prompt a search for an underlying debilitating condition or a breakdown in the skin or mucosa of areas where group G streptococci may be normal flora, including the gastrointestinal tract.

The association of group G streptococcal arthritis and colonic abnormalities, as demonstrated in our patients, is an infrequently recognized enteropathic arthropathy. Further studies of a greater number of cases will be necessary for us to understand more fully the pathophysiology of this disease.

\section{References}

1. Resnick D: Enteropathic arthropathies. In Resnick D, Niwayama G (eds): Diagnosis of Bone and Joint Disorders. Philadelphia: W.B. Saunders, 1981, pp 1149-1177

2. Lin AN, Karasik A, Salit IE, Fam AG: Group G streptococcal arthritis. $J$ Rheumatol 9:424 427, 1982

3. Coto $\mathrm{H}$, Gage $\mathrm{K}$, Ekenna $\mathrm{O}$, Berk $\mathrm{S}$ : Bacteremic group G streptococcal septic arthritis. J Tenn Med Assoc $75: 594-596,1982$

4. Fujita NK, Lam K, Bayer AS: Septic arthritis due to group G streptococcus. JAMA 247:812-813, 1982

5. Lam K, Bayer AS: Serious infections due to group G streptococci. Am J Med 75:561-570, 1983

6. Nakata MM, Silvers JH, George WL: Group G streptococcal arthritis. Arch Intern Med 143:1328-1330, 1983

7. Russell AS, Ansell BM: Septic arthritis. Ann Rheum Dis 31: $40-44,1972$

8. Watsky KL, Kollisch N, Densen P: Group G streptococcal bacteremia. Arch Intern Med 145:58 61, 1985

9. Resnick D, Niwayama G: Osteomyelitis, septic arthritis, and soft tissue infection: the mechanisms and situations. In Resnick D, Niwayama G (eds): Diagnosis of Bone and Joint Disorders. Philadelphia: W.B. Saunders, 1981, pp 2042-2129

10. Armstrong D, Blevins A, Louria DB, Henkel JS, Moody $\mathrm{MD}$, Sukany M: Groups B, C, and G streptococcal infections in a cancer hospital. Ann NY Acad Sci 174:511-522, 1970

11. Rose HJ, Fiske S, Weisbrodt F, Smith LG: Group G streptococcal endocarditis in a patient with adenocarcinoma of the colon. I Med Soc NJ 76:671-672, 1979

Received: July 1, 1986; accepted: September 2, 1986 